Artigo Original

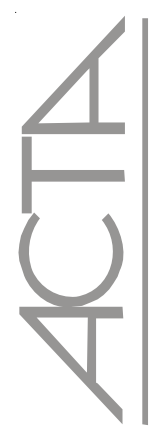

\title{
Validação de um instrumento de registro para sala de recuperação pós-anestésica*
}

\author{
Content validity of an instrument to document recovery of patients in post anesthesia care unit
}

Validación de un instrumento de registro para la sala de recuperación pos anestésica

\section{Ana Lúcia Silva Mirancos da Cunha ${ }^{1}$, Aparecida de Cássia Giani Peniche $^{2}$}

\begin{abstract}
RESUMO
Objetivo: validar o conteúdo de um instrumento de registro para avaliação do paciente na unidade de recuperação pós-anestésica. Métodos: utilizou-se a técnica Delphi para a coleta de dados que se procedeu em duas fases. Resultados: os resultados obtidos mostraram que dos 8 itens que compunham o instrumento 7 deles $(87,5 \%)$ foram mantidos e todos com algum tipo de alteração, sendo que os itens de: admissão e de avaliação de sinais vitais, índice de Aldrete e Kroulik e índice pediátrico, prescrição de enfermagem e o espaço para anotação obtiveram consenso de $100 \%$ dos juízes para que fossem mantidos no instrumento. Para 11 juízes (79\%) o item diversos encontrava-se bastante repetitivo devendo ser excluído. Outro item mantido, pela concordância de $64 \%$ dos juízes, foi a avaliação do paciente na admissão e alta da sala de recuperação, apesar de ser aquele com maior índice de alterações. Após as alterações sugeridas, o instrumento foi modificado, reenviado, e analisado novamente pelos juízes, porém estas não atingiram a concordância mínima estabelecida pela técnica utilizada. Conclusão: considerou-se após estas duas fases que o instrumento foi validado quanto ao seu conteúdo e forma de apresentação, sendo necessárias adequações, de acordo com o tipo de pacientes e de instituição.

Descritores: Registros de enfermagem; Assistência de enfermagem; Cuidados pós-operatórios/enfermagem
\end{abstract}

\begin{abstract}
Objective: To determine the content validity of an instrument to document the assessment and recovery of surgical patients in post anesthesia care unit (PACU). Methods: Delphi technique was used to conduct this two-phase study. Results: Items on admission and vital signs, Audrete and Kroulik index, pediatric index, nursing orders, and progress notes reached $100 \%$ consensus among expert judges. Items regarded as being repetitive by $79 \%$ of experts were revised or excluded from the instrument. Following this procedure, items of the instruments were again evaluated by the experts and new revisions were made as appropriate to achieve minimum agreeement among experts as recommended by Delphi technique. Conclusion: The instrument was validated regarding its content and format. Further analysis might be necessary according to hospital and type of patient admitted to the PACU.
\end{abstract}

Keywords : Nursing records; Nursing care; Postoperative care/nursing

\section{RESUMEN}

Objetivo:objetivo de este estudio fue proporcionar un instrumento de registro para evaluar los pacientes en la sala de recuperación anestésica y validar su contenido. Metodos:para tal finalidad fue utilizada la técnica Delphi. Resultados: los resultados obtenidos mostraron que de ocho ítems, siete (87.5\%) fueron ratificados, mientras que para los jueces los ítems de admisión y evaluación de sinais vitais, índice de Aldrete e kroulik y índice de pediatria, prescripción de enfermería y/o espacio para anotación fueron 100\% mantenidos sin cambio. Después de las alteraciones sugeridas, el instrumento fue modificado y reenviado a los jueces, quienes nuevamente analizaron el instrumento sugiriendo nuevos cambios. Conclusión: consideramos que después de estas dos fases la herramienta fue validada en cuanto a su contenido y forma de presentación, pudiendo haber adecuaciones de acuerdo con el tipo de institución y de pacientes atendidos en la sala de recuperación pos anestésica.

Descriptores: Registros de enfermería; Atención enfermería; Cuidados postoperatórios/enfermería

${ }^{*}$ Trabalho realizado na Recuperação Anestésica do Hospital Sirio Libânes - São Paulo (SP), Brasil.

${ }^{1}$ Mestre em Enfermagem; Coordenadora Operacional do Bloco Cirúrgico do Hospital Sírio Libanês, São Paulo (SP), Brasil.

${ }^{2}$ Professor Livre Docente do Departamento de Enfermagem Médico Cirúrgica da Escola de Enfermagem da Universidade de São Paulo - USP - São Paulo (SP), Brasil. 


\section{INTRODUÇÃO}

O período de recuperação pós-anestésica é definido por Bello ${ }^{(1)}$, como aquele compreendido entre a interrupção da administração de anestésicos e o retorno das condições basais do paciente. Esse espaço de tempo é avaliado pela monitorização das funções vitais do paciente, associado ou não aos exames subsidiários, incluindo, naturalmente, o diagnóstico e o tratamento de complicações.

Ainda segundo este mesmo autor este intervalo processa-se em três fases: Imediata (minutos) onde o paciente apresenta retorno da consciência e a presença de reflexos das vias aéreas superiores, além da movimentação; Intermediária (minutos/horas) quando ocorre o restabelecimento da coordenação motora e atividade sensorial; Tardia (dias) com a normalidade das funções motora e sensorial.

Desde 1993, foi estabelecido pelo Decreto lei (Resolução CFM no. 1363/93 ) que este período deveria ocorrer em área física planejada, denominada de Sala de Recuperação pós-anestésica (SRPA) com uma equipe multiprofissional composta de anestesiologista, enfermeiro e técnico/auxiliar de enfermagem, treinada e habilitada a prestar cuidados individualizados de alta complexidade .

Com o objetivo de auxiliar a equipe nesta atividade e proporcionar uma avaliação segura e contínua das condições gerais dos pacientes na SRPA, em 1970, Aldrete e Kroulik ${ }^{(2)}$ propuseram um índice semelhante ao utilizado na avaliação das condições fisiológicas dos recém nascidos (APGAR). Assim, os autores pontuaram de 0 a 2 a variação da freqüência de pulso, freqüência respiratória, pressão arterial, estado de consciência, atividade motora e, recentemente, a saturação de oxigênio por considerarem estes parâmetros clínicos como marcadores dos sistemas fisiológicos comprometidos pelo procedimento anestésico.

Vários autores ${ }^{(3-6)}$ pela vulnerabilidade em que os pacientes se encontram, e pelas intercorrências serem comuns e freqüentes nesta fase, propuseram, além do índice existente, a reestruturação nos instrumentos de registros utilizados.

Mas só a reestruturação nos instrumentos de registros, enfocando a avaliação dos sistemas fisiológicos afetados pelo procedimento anestésico cirúrgico, parece não ser suficiente para garantir um período de recuperação anestésica livre de riscos e complicações. São necessários registros claros e fidedignos, que retratem o quadro clínico real do paciente.

$\mathrm{Na}$ prática diária, observa-se que a equipe de enfermagem da SRPA realiza muitas ações de assistência ao paciente e que, diante da instabilidade e da alta rotatividade nesta unidade, são necessárias ações rápidas, para evitar complicações, assim como os registros corretos destas ações em instrumentos apropriados para garantir uma continuidade dos cuidados iniciados.

Entende-se como registro apropriado aquele que, ao ser consultado, traz de uma forma clara e concisa as informações necessárias do momento ${ }^{(7-8)}$.

Domingues e Coutinho( ${ }^{(9)}$ fazem uma ressalva quanto ao excesso de "impressos e registros", cuja real necessidade merece ser analisada no período de recuperação pós-anestésica .

Sabe-se que em períodos de grande movimento em SRPA admitem-se vários pacientes simultaneamente, ocasionando uma observação superficial e, conseqüentemente, a mecanização do cuidado, resultando em uma anotação de enfermagem que na maioria das vezes não retrata a realidade.

De acordo com alguns autores ${ }^{(10-12)}$ a documentação facilita a comunicação entre os membros da equipe de saúde, promove a continuidade da assistência, reflete o plano de cuidados e serve como um registro legal do cuidado fornecido. Também referem que a documentação das atividades de enfermagem realizada tem seu aspecto legal e é profissionalmente importante, assim como propicia uma comunicação clara e muita colaboração entre os membros da equipe de saúde, assegurando a continuidade do cuidado ao paciente.

Diante desta realidade e como enfermeira coordenadora de SRPA senti necessidade de reformular o instrumento até então utilizado.

Inicialmente, foi elaborado um instrumento de registro constituído dos seguintes itens: identificação do paciente: (nome, idade, leito de origem hora de chegada, tipo de cirurgia e nome do cirurgião; tipo de anestesia e nome do anestesista, antecedentes clínicos, sinais vitais do período pré-operatório, patologias prévias, alergias e relação de exames trazidos pelo paciente), além de avaliação de sinais vitais de 15 em 15 minutos (temperatura, pulso, pressão arterial, freqüência respiratória, saturação de oxigênio, pressão arterial média, pressão venosa central, dor) índice de Aldrete e Kroulik (IAK), índice pediátrico (IP), prescrição médica, anotação de infusões, sangue e derivados, glicosometria, líquidos eliminados e diversos (presença ou não de cânula, cateteres, sondas, drenos, meias elásticas, massageador). Foi também incluída avaliação de comportamento e dos vários sistemas fisiológicos (respiratório, neurológico, digestivo, renal, tegumentar, cardiovascular), avaliação da incisão cirúrgica, prescrição, evolução e anotação de enfermagem. Inseriu-se também dados referentes ao momento da alta do paciente como: estado de consciência, infusões, analgesia, condições do curativo, dreno diurese, perfusão periférica, massageador, objetos do paciente encaminhados, responsável pelo recebimento do paciente, além de um espaço para observações. 
Após a elaboração deste instrumento de registro o passo seguinte foi propor o objetivo deste estudo.

\section{OBJETIVO}

Validar o conteúdo do instrumento de registro proposto para avaliação do paciente em SRPA.

\section{MÉTODO}

Utilizou-se a técnica Delphi para a coleta de dados. A técnica Delphi é um método de obtenção de opiniões e critérios de um conjunto de especialistas, onde é feito um questionamento individual e cujas respostas obtidas são apresentadas a esses mesmos especialistas, e em seguida, novo interrogatório é feito onde são introduzidas as informações relativas às interações até a obtenção de um consenso. Esta dinâmica confere ao instrumento avaliado uma consolidação do julgamento intuitivo do grupo de especialistas, sem necessidade de um painel de discussões ${ }^{(13-15)}$.

\section{Procedimento de coleta}

Após a aprovação do Comitê de Ética em Pesquisa do Hospital Sírio Libanês foi realizada a coleta de dados em duas fases. Fase 1: Num primeiro momento entrouse em contato com a Sociedade Brasileira de Enfermeiros em Centro Cirúrgico, Recuperação Anestésica e Central de Material Esterilizado que forneceu uma listagem de enfermeiros que atuavam em unidade de recuperação anestésica, nas áreas assistencial, de ensino ou de pesquisa da cidade de São Paulo. O próximo passo foi realizar um primeiro contato por telefone ou via e-mail com enfermeiros que tivessem, no mínimo, uma experiência de dois anos na referida área. Obteve-se então 15 profissionais, sendo nove enfermeiros assistências, três enfermeiros docentes de universidades públicas e três de universidades privadas. Agendou-se uma data oportuna, quando foram apresentados o objetivo e a finalidade da pesquisa, em seguida questionou-se sobre a concordância em participar da mesma, e mediante aceitação, foram prestados maiores esclarecimentos sobre o estudo, bem como sobre o método escolhido (técnica Delphi). Em seguida, entregou-se o questionário de análise do instrumento de registro acompanhado do instrumento de registro e o Termo de Consentimento Livre e Esclarecido em duas vias, ficando uma cópia assinada com o juiz e outra com o pesquisador. Foi ainda solicitada a devolução da análise do instrumento no prazo de 15 dias. Expirado este prazo, excluiu-se um juiz da amostra em virtude do não cumprimento do prazo de devolução do questionário. Sendo assim, restaram 14 juízes.

Cabe ressaltar que a técnica Delphi utilizada permite que o número de juízes seja determinado diretamente pelo fenômeno que se pretende estudar, podendo variar, segundo alguns autores de 7 a 12 juízes ${ }^{(16-18)}$.

Após a devolução dos questionários de análise, os instrumentos de registro foram modificados conforme as sugestões oferecidas e iniciada a Fase 2: $\mathrm{O}$ instrumento de registro modificado (Anexo A) foi reenviado aos 14 juízes, desta vez eletronicamente, com um prazo de devolução de 15 dias, os quais novamente os analisaram e sugeriram pequenas alterações, que foram incorporadas ou não, segundo os critérios de conveniência citados a seguir: uma concordância entre os juízes igual ou superior a $65 \%$ para ocorrer a manutenção ou exclusão do item no instrumento de registro, associado a $55 \%$ de sugestões de alterações e mediante a concordância de dois ou mais juízes. Nesta segunda fase encerrou-se a coleta de dados, uma vez que (8- $57,2 \%$ ) dos juízes, apesar de pontuarem algumas sugestões, estas não obtiveram a concordância mínima exigida (2 ou mais juizes) e os outros 6 juízes ( $43 \%$ ) alegaram não ter mais nenhuma modificação a fazer.

\section{Instrumento}

O questionário de análise é dividido em duas partes: Parte I: Consta de dados de identificação dos juízes como formação profissional (tipo de escola em que se formou e tempo de formação), tempo de experiência profissional em SPRA e instituição em que trabalha, se pública ou privada.Parte II: Contém todos os itens do instrumento de registro proposto, vinculado ao julgamento. Como exemplo, no que refere a identificação do paciente: Dados de identificação do paciente referentes ao tipo de anestesia, cirurgia realizada antecedentes clínicos, sinais vitais e exames pré-operatórios deve-se: manter sem ou com alterações e quais; não manter. Além de possuir espaços para comentários dos juízes quanto à pertinência ou não dos itens, seguido de sugestões feitas e alterações.

\section{RESULTADOS}

Dos 14 enfermeiros que fizeram parte da amostra, sete $(50 \%)$ possuem graduação em escola privada, seis $(43 \%)$ em escola pública e um $(7 \%)$ em entidade filantrópica. Com relação ao tempo de graduação, seis enfermeiros (43\%) são graduados há mais de 10 anos, quatro (29\%) entre 5 a 10 anos e quatro $(29 \%)$ de 2 a 5 anos. No que se refere à experiência na área de recuperação pós-anestésica, cinco enfermeiros $(36 \%)$ tem mais de 10 anos de experiência na área, um (7\%) com 5 a 10 anos, dois (14\%) de 3 a 5 anos e seis (43\%) de 1 a 3 anos. A maioria dos juízes (12-86\%) possui algum curso de pós-graduação, trabalha no setor privado (10-71,43\%), e quatro $(28,57 \%)$ pertencem ao setor público.

\section{Validação do conteúdo}

Os quatorze juízes $(100 \%)$ optaram por manter os dados de identificação do paciente. Seis dos juízes (42,8\%) 
mantiveram o item sem qualquer alteração e oito deles $(57,1 \%)$ solicitaram alguma modificação, dentre elas acrescentar a avaliação fisiológica estabelecida pela Anesthesiology Society Association (ASA) e aumentar o espaço para preenchimento deste item, além de inserir o tempo de permanência em sala de operações.

Com relação à monitorização dos sinais vitais, foi mantido o item por $100 \%$ dos juízes, sendo que doze juízes $(86 \%)$ sugeriram incluir nesta monitorização a escala de sedação; mudar o intervalo de mensuração dos parâmetros de acordo com condições fisiológicas de cada paciente, de suas condições pregressas, do tipo de anestesia e cirurgia.

Outra alteração foi retirar glicosometria como item e o acréscimo do balanço hídrico parcial e total. O espaço reservado para anotação de "Diversos" se mostrou para $11(79 \%)$ juízes, como repetitivo sendo então excluído. Os itens referentes às avaliações de comportamento, dos vários sistemas e da incisão cirúrgica foram mantidos por 13 juízes $(93 \%)$ sendo que nove (64\%) deles propuseram alguma alteração como a substituição da palavra digestiva por digestório e, na avaliação do sistema nervoso central, a retirada da avaliação pupilar, além de alterações na forma de identificação da sujidade do curativo. Os índices de Aldrete e Kroulik e de avaliação pediátrica permaneceram sem alterações.

Quanto à prescrição de enfermagem todos os 14 juízes $(100 \%)$ concordaram com a sua manutenção no instrumento, porém sugeriram alterações como retirar prescrição de rotinas (manter grades elevadas, rodas travadas e avaliar parâmetros).

$\mathrm{O}$ item referente às condições de alta do paciente foi considerado importante para 13 (93\%) juízes e oito destes sugeriram a retirada do subitem referente à anotação da nutrição parenteral.

\section{DISCUSSÃO}

Considerando as especificidades da assistência de enfermagem em SRPA, este método possibilitou uma visão ampla e aprofundada das necessidades, relacionadas ao registro dos cuidados prestados, pelos enfermeiros que atuam nesta área. A discussão dos resultados está pautada nas sugestões feitas por especialistas (juízes) e vai desde a permanência, inclusão, exclusão de itens até a forma de grafia e formatação dos mesmos, resultando em um instrumento adequado e pertinente ao que se destina.

Entende-se como registro apropriado aquele que, ao ser consultado, traz de uma forma clara e concisa as informações necessárias para o momento.

Autores ${ }^{(11)}$ relata que a anotação constitui fato importante para informar a todos os profissionais sobre às condições clínicas do paciente, evolução do tratamento e avaliação do resultado, e ainda fornece dados de valor legal, contribuindo para a segurança tanto do paciente, do profissional como da instituição. Ressaltam, ainda, a importância da anotação como fornecedora de dados para a pesquisa e ensino.

As anotações de enfermagem, quando sistematizadas, oferecem maior possibilidade de serem completas, e podem agregar informações que auxiliam na tomada de decisões e, conseqüentemente, contribuem para a redução do tempo que seria utilizado com informações difusas. Em decorrência deste fato, a assistência de enfermagem na SRPA se torna eficiente, além de possibilitar uma avaliação racionalizada das condições físicas do paciente, podendo ser adotada de forma sistemática ${ }^{(8,17)}$.

O enfermeiro vê na sistematização da assistência de enfermagem uma forma segura de prestar o cuidado necessário, desde que haja a racionalização do tempo utilizado para isto, uma vez que o excesso de burocracia, no que se refere ao preenchimento de vários impressos, dificulta ou até afasta a equipe de enfermagem do atendimento direto aos pacientes ${ }^{(9)}$.

O Sistema de Assistência de Enfermagem pelas suas características e finalidades, parece contribuir com esta demanda apresentada. Porém, segundo dados apresentados pelo Conselho Regional de Enfermagem, apesar de ser obrigatória sua implantação desde 1999, $65 \%$ das instituições hospitalares não sabem como fazê$1 a^{(17)}$.

Acredita-se que, principalmente na unidade de SRPA, esta dificuldade de implantação acentua-se pela alta complexidade e rotatividade dos pacientes, porém não justifica a inexistência de ferramentas que garantam a continuidade da assistência prestada ao paciente cirúrgico ${ }^{(16)}$.

Segundo a Sociedade Brasileira de Enfermeiros de Centro Cirúrgico, Recuperação Anestésica e Central de Material e Esterilização ${ }^{(18)}$ os dados como identificação, diagnóstico médico, antecedentes patológicos, alergias a drogas, tipos de cirurgia e anestesia realizada, problemas e complicações ocorridas durante a cirurgia, entre outras, são necessários para a implementação do cuidado de enfermagem.

Para Burns ${ }^{(19)}$ é essencial que o enfermeiro esteja alerta a qualquer informação pertinente sobre a história préoperatória que possa ser significativa neste momento.

Welter; Reiff ${ }^{(20)}$ relatam que algumas informações devem estar disponíveis para que a enfermeira de SRPA possa entender as condições do paciente e priorizar seus cuidados no período pós-operatório imediato. São elas: nome e idade do paciente; tipo de cirurgia e nome do cirurgião; tipo de anestesia e nome do anestesiologista; tipos e localização de drenos, curativos e vestimentas; alergias; história pregressa; hábitos e costumes; cirurgias anteriores; sinais vitais do período intra-operatório; tipos 
de medicamentos recebidos; complicações do intraoperatório; nível de consciência; posicionamento no intraoperatório; temperatura; balanço hídrico.

Como se observa, todos estes dados de importância para a avaliação do paciente constam no instrumento em questão.

Além da avaliação pré-operatória feita e de dados registrados no prontuário, alguns índices utilizados facilitam na determinação de risco existente para o paciente, aqui a opção foi o proposto pela American Society Anestesiology que estabelece critérios, pautados na avaliação do estado físico, para identificar o risco de morbidade dos pacientes cirúrgicos.

A evolução do paciente e sua avaliação contínua foi o ponto salientado pelos juízes. As principais metas da assistência de enfermagem para que o paciente tenha uma recuperação considerada ótima incluem função respiratória, alívio da dor e dos desconfortos pósoperatórios, manutenção da temperatura corporal normal, entre outras ${ }^{(9)}$.

De acordo com a American periOperative Room Nurses ${ }^{(11-12)}$ os cuidados no período pós-operatório, a monitoração e os critérios de alta devem ser consistentes para todos os pacientes. O tempo de recuperação depende do tipo e da quantidade da sedação/analgesia aplicada, do resultado do procedimento e da política do serviço. Nessa fase a avaliação pós-operatória compreende a verificação da freqüência respiratória e ritmo cardíaco, do nível de consciência, da saturação de oxigênio e da medida de pressão arterial, assim como da observação das condições da ferida e do curativo, da permeabilidade das vias de acesso e das drenagens e da avaliação do nível de dor do indivíduo. É essencial que o enfermeiro saiba reconhecer a importância dos sinais e sintomas na previsão e no impedimento dos problemas no pós-operatório. De acordo com estes fatos, é prudente determinar que a avaliação dos parâmetros seja realizada conforme prescrição de enfermagem após a avaliação do paciente pelo enfermeiro.

Para tanto, todos os parâmetros existentes no instrumento são importantes; assim como inclusão da escala de Ramsay para a avaliação da dor pós-operatória uma vez que os pacientes encontram-se torporosos o que inviabiliza a utilização de quaisquer outras escalas numéricas e verbais para este fim.

Com relação ao resumo das condições de alta, entendese que a manutenção do item reflete uma das grandes preocupações dos juízes, relacionadas à continuidade da assistência de enfermagem na SRPA, ou seja, não perder informações importantes referentes ao cuidados prestados até o momento da alta pois, na prática diária, existe uma dificuldade ou até mesmo uma lacuna entre os setores na obtenção de informações pertinentes a este período, o que gera dúvidas no prosseguimento do cuidado específico.

\section{CONCLUSÃO}

O instrumento proposto foi formulado com a finalidade de abranger todos os itens que devem ser observados nos paciente ao se prestar cuidados em SRPA separando-os em sistemas para que facilitassem a equipe de enfermagem em sua atuação neste serviço, isto é, um guia do que deve ser observado e avaliado. Porém, o mesmo, em primeira análise feita pelos juízes, se mostrou com um volume aumentado de itens e também repetitivo, levando-os ao questionamento do tempo hábil para o seu correto preenchimento.

O instrumento final obtido (Anexo A), segundo os juízes que o analisaram, foi considerado fundamental para a assistência do paciente na SRPA, classificando-o como completo, permitindo um fluxo de comunicação escrita e favorecendo a continuidade do processo de assistência de enfermagem ao paciente cirúrgico no período pósoperatório.

Considera-se o instrumento validado quanto ao seu conteúdo e forma de apresentação, porém sugere-se que adequações sejam realizadas, de acordo com o tipo de instituição e do paciente atendido no centro cirúrgico.

Para o seu correto preenchimento são necessários o treinamento constante do enfermeiro de SRPA, seguido de avaliações periódicas para o acréscimo ou substituição de itens que possam ser importantes a cada instituição.

A realização de outros estudos é necessária, com ampliação do quadro de juízes, com aplicação do instrumento em serviços de complexidades diferentes.

Espera-se que, com este estudo, a assistência de enfermagem na área de recuperação pós-anestésica seja investigada e tenha o aprofundamento necessário que a especificidade do paciente exige nesta fase, isto é, que este período pós-operatório seja seguro e com o menor índice de complicações possíveis pautados não só, mas também em uma equipe de enfermagem treinada e habilitada, não só nos cuidados específicos, como também nos registros corretos e adequados destas atividades.

\section{REFERÊNCIAS}

1. Bello CN. Recuperação pós-anestésica - escalas de avaliação, princípios gerais. CEDAR - Centro de Estudos de Anestesiologia e Reanimação da Disciplina de Anestesiologia da FMUSP, 2000;Ano IV:4-9.

2. Aldrete JA, Kroulik D. A postanesthetic recovery score. Anesth Analg. 1970; 49(6):924-34.

3. Steward DJ. A simplified scoring system for the postoperative recovery room. Can Anaesth Soc J. 1975; 22(1):1113.

4. Posso MBS. Avaliação das condições dos pacientes na sala de recuperação pós-anestésica. Rev Esc Enfermagem USP. 1975; 9(3):9-23. 
5. Castanos CC. Índices de recuperação. Rev Bras Anestesiol. 1982; 32(6):441-2.

6. Peniche ACG. Algumas considerações sobre avaliação do paciente em sala de recuperação anestésica. Rev Esc Enfermagem USP. 1998; 32(1):27-32.

7. Meeker MH, Rothrock JC. Cuidados básicos de enfermagem perioperatória. In: Meeker MH, Rothrock JC. Alexander cuidados de enfermagem ao paciente cirúrgico. 10a ed. Rio de Janeiro: Guanabara Koogan; 1997. p.3-17.

8. Januncio IM. Análise das anotações de enfermagem no período perioperatório: subsídios para a continuidade da assistência prestada a pacientes de cirurgia cardíaca [tese]. São Paulo: Escola de Enfermagem da Universidade de São Paulo; 2002.

9. Domingues C, Coutinho RMC. Assistência de enfermagem na sala de recuperação anestésica. Rev SOBECC. 1998; 3(2): 14-6.

10. American Society of Anesthesiologists Task Force on Postanesthetic Care. Practice guidelines for postanesthetic care: a report by the American Society of Anesthesiologists Task Force on Postanesthetic Care. Anesthesiology. 2002; 96(3):742-52.

11. Teixeira MB, Prates JB, Almeida JG. Avaliação da qualidade das anotações de enfermagem. HC Enfermagem. 1998; 3(3/ 4):8-10.

12. Padovani P, Gatto MAF, Peniche ACG. Ficha de recuperação anestésica: avaliação dos dados oferecidos para o planejamento da assistência de enfermagem no pósoperatório imediato. Enfoque (São Paulo). 1988; 16(2): 458.

13. Spínola AWP. Delfos; proposta tecnológica alternativa. São
Paulo: Faculdade de Saúde Pública; 1984.

14. Faro ACM. Técnica Delphi na validação das intervenções de enfermagem. Rev Esc Enfermagem USP. 1997; 31(2):25973.

15. Philips R. New applications for the Delphi technique. In: 2000 Annual. San Francisco (CA): Jossey-Bass/Pheiffer; 2000. p. 191-6.

16. Reda E. Instrumento de registro utilizado na avaliação em sala de recuperação pós-anestésica: importância na continuidade da assistência ao paciente cirúrgico [tese]. São Paulo: Escola de Enfermagem da Universidade de São Paulo; 2006.

17. Conselho Regional de Enfermagem do Estado de São Paulo (COREN - SP). Decisão 008 de 19 de outubro de 1999 (DIR/ 008/1999). Normatiza a Implementação da Sistematização da Assistência de Enfermagem (SAE) nas Instituicões de Saúde, no âmbito do Estado de São Paulo. São Paulo: COREN-SP; 1999.

18. Sociedade Brasileira de Enfermeiros de Centro Cirúrgico, Recuperação Pós-Anestésica e Centro de Material e Esterilização. Práticas recomendadas - SOBECC. 2. ed. rev. e atual. São Paulo: SOBECC; 2003. p.78-88.

19. Burns LS. Assistência de enfermagem no período pósoperatório: In: Smeltzer SC, Bare BG. Brunner \& Suddarth: tratado de enfermagem médico-cirúrgica. In: Smeltzer SC, Bare BG. Brunner \& Suddarth: tratado de enfermagem médico-cirúrgica. 9a ed. Rio de Janeiro: Guanabara-Koogan; 2002. cap.18, p.337-60

20. Welter ER, Reiff PA. Transferring patients from the OR. What the postanesthesia room nurse needs to know. AORN J. 1989; 50(6):1248-50, 1252. 


\section{ANEXO A}

RECUPERAÇÃO ANESTÉSICA

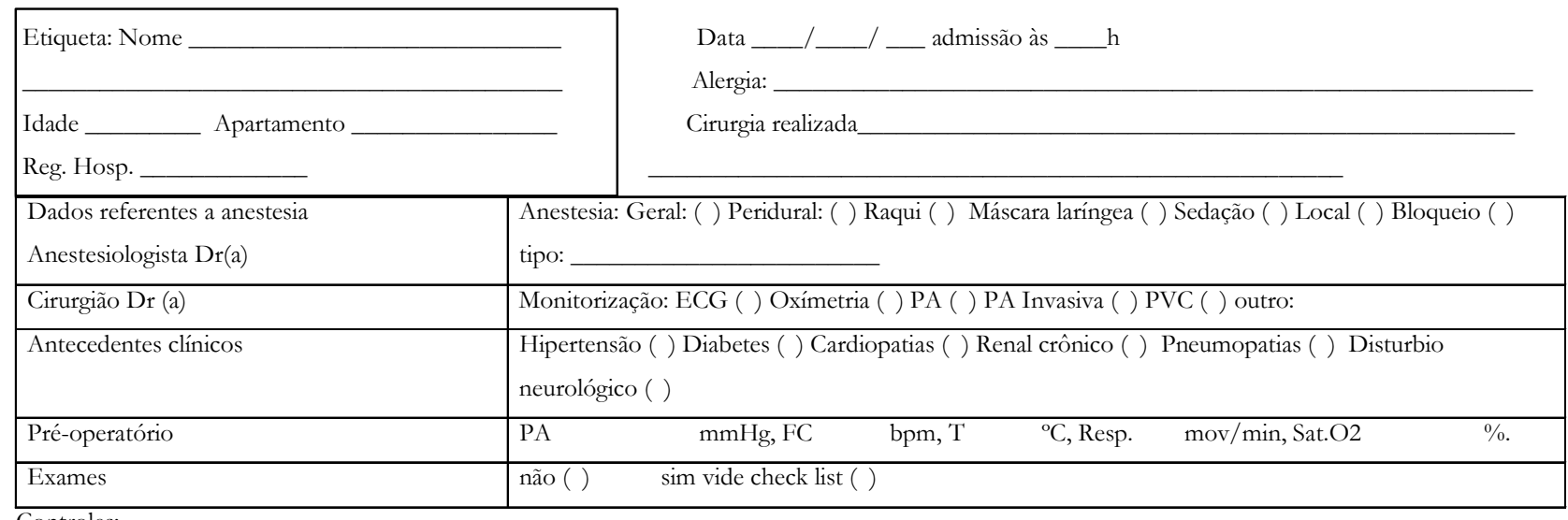

Controles:

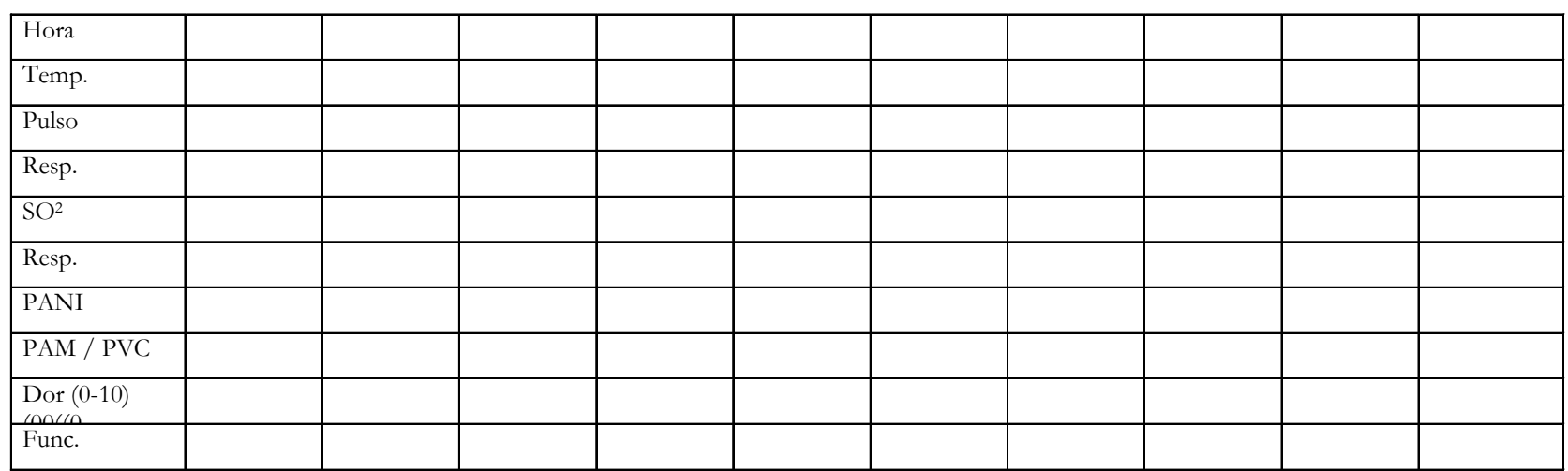

Indice de Aldrete kroulik (paciente adulto)

\begin{tabular}{|c|c|c|c|c|c|c|c|}
\hline & Tempo em minutos & valor & adm & 30 & 60 & 120 & observação \\
\hline \multirow{3}{*}{$\begin{array}{l}\text { Atividade } \\
\text { motora sob } \\
\text { comando }\end{array}$} & Capaz de mover os 4 membros & 2 & & & & & \\
\hline & Capaz de mover 2 membros & 1 & & & & & \\
\hline & Incapaz de mover os membros & 0 & & & & & \\
\hline \multirow{3}{*}{ Respiração } & respira profundamente ou tosse livremente & 2 & & & & & \\
\hline & Dispnéia ou limitação da respiração & 1 & & & & & \\
\hline & Apnéia & 0 & & & & & \\
\hline \multirow{3}{*}{ Circulação } & PA $20 \%$ do nível pré-anestésico & 2 & & & & & \\
\hline & PA $20-49 \%$ do nível pré-anestésico & 1 & & & & & \\
\hline & PA $50 \%$ do nível pré-anestésico & 0 & & & & & \\
\hline \multirow{3}{*}{ Consciência } & Lúcido, orientado no tempo e espaço & 2 & & & & & \\
\hline & Desperta se solicitado & 1 & & & & & \\
\hline & Não responde & 0 & & & & & \\
\hline \multirow{3}{*}{$\begin{array}{c}\text { Saturação } \\
\text { de } \mathrm{O}_{2}\end{array}$} & Maior que $92 \%$ respirando em ar ambiente & 2 & & & & & \\
\hline & Necessita de $\mathrm{O}_{2}$ para manter sat $\mathrm{O}_{2}$ maior que $90 \%$ & 1 & & & & & \\
\hline & Menor que $90 \%$ com $\mathrm{O}_{2}$ suplementar & 0 & & & & & \\
\hline \multirow[t]{2}{*}{ IAK } & Total & & & & & & \\
\hline & Carimbo & & & & & & \\
\hline
\end{tabular}

Nota: valor mínimo para alta -8 pontos

Prescrição médica:

Instalar nebulização com $\mathrm{O}_{2}$ continuo com $\mathrm{H} 2 \mathrm{O}$ destilada de $250 \mathrm{ml}$ de 8 a 101/min I h T h 
Índice de Avaliação pediátrico ( 0 - 12 anos) baseado em Stward

\begin{tabular}{|c|c|c|c|c|c|c|c|}
\hline Tempo & em minutos & Valor & $\mathrm{adm}$ & 30 & 60 & 120 & observação \\
\hline \multirow{3}{*}{$\begin{array}{c}\text { Saturação } \\
\text { de } \mathrm{O}_{2}\end{array}$} & Maior que $95 \%$ respirando em ar ambiente & 2 & & & & & \\
\hline & Necessita de $\mathrm{O}_{2}$ para manter sat $\mathrm{O}_{2}$ maior que $90 \%$ & 1 & & & & & \\
\hline & Menor que $90 \%$ com $\mathrm{O}_{2}$ suplementar & 0 & & & & & \\
\hline \multirow{3}{*}{$\begin{array}{c}\text { Vias } \\
\text { aéreas }\end{array}$} & Tosse ou choro & 2 & & & & & \\
\hline & Boa manutenção/ respira facilmente & 1 & & & & & \\
\hline & Requer manutenção & 0 & & & & & \\
\hline \multirow{3}{*}{ Consciência } & Disperto & 2 & & & & & \\
\hline & Responde a estímulos verbais ou táteis & 1 & & & & & \\
\hline & Não responde & 0 & & & & & \\
\hline \multirow{5}{*}{ Movimentação } & Movimenta os membros intencionalmente & 2 & & & & & \\
\hline & Movimentos não intencionais & 1 & & & & & \\
\hline & Não se movimenta & 0 & & & & & \\
\hline & Total & & & & & & \\
\hline & Carimbo & & & & & & \\
\hline
\end{tabular}

Nota: valor mínimo para alta -6 pontos

Infusão / soluções

\begin{tabular}{|c|c|c|c|c|c|c|c|c|c|}
\hline Volume & Descrição & Quantidade & Hora & Hora & Hora & Hora & Hora & Hora & $\mathrm{H}$ \\
\hline \multirow[t]{2}{*}{$1000 \mathrm{ml}$} & S. Fisiológico & & & & & & & & \\
\hline & S. Fisiológico & & & & & & & & \\
\hline \multirow[t]{2}{*}{$500 \mathrm{ml}$} & Ringer Lactato & & & & & & & & \\
\hline & S. Glicosado & & & & & & & & \\
\hline & & & & & & & & & \\
\hline & & & & & & & & & \\
\hline
\end{tabular}

\begin{tabular}{|c|c|c|c|c|c|c|c|}
\hline \multicolumn{8}{|c|}{ Sangue e derivados } \\
\hline Descrição & Hora & $\mathrm{N}^{\circ}$ da bolsa & Volume & Hora & $\mathrm{N}^{\circ}$ da bolsa & Volume & Quanti \\
\hline \multicolumn{8}{|c|}{ Concentrado de glóbulos } \\
\hline \multicolumn{8}{|l|}{\begin{tabular}{|l|} 
Plasma \\
\end{tabular}} \\
\hline Plaquetas & & & & & & & \\
\hline & & & & & & & \\
\hline
\end{tabular}

Glicosometria
\begin{tabular}{|c|c|c|c|c|c|c|c|c|c|}
\hline Hora & Valor & Hora & Valor & Hora & Valor & Hora & Valor & Hora & Valor \\
\hline & & & & & & & & & \\
\hline
\end{tabular}

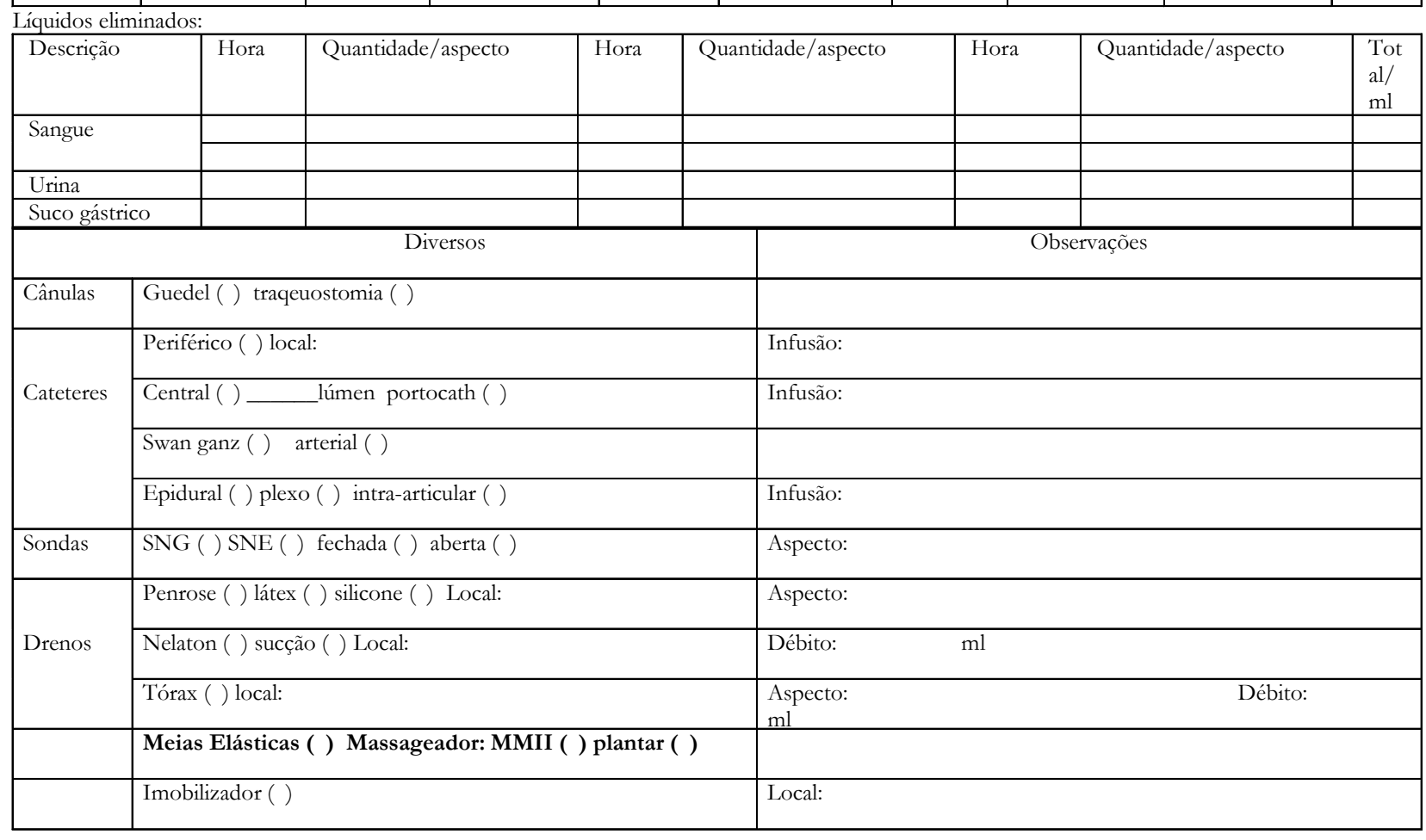


Avaliação das condições do paciente na admissão e alta

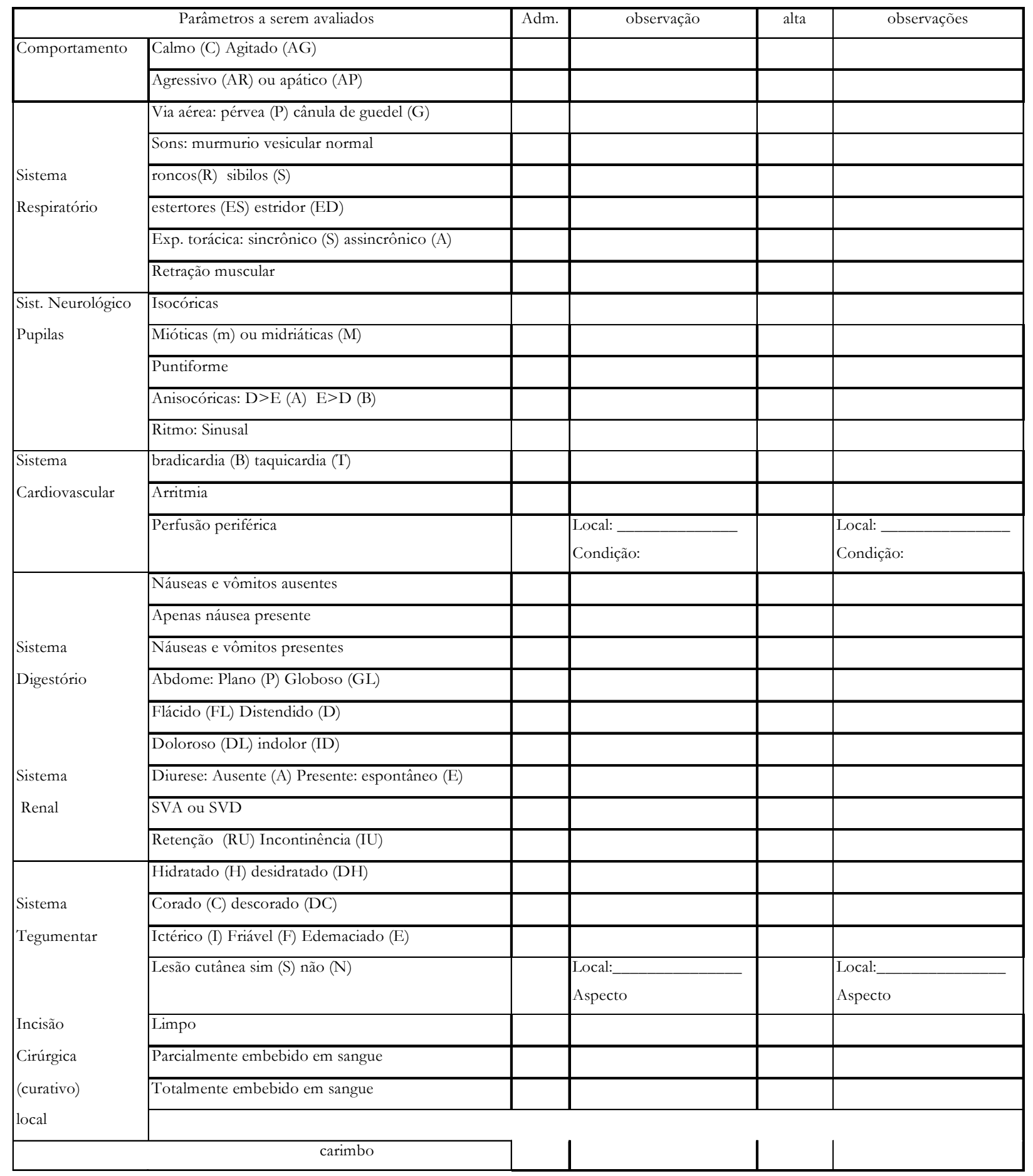


Prescrição de enfermagem

\begin{tabular}{|c|c|c|}
\hline & Ação de enfermagem & Carimbo (tec/aux) \\
\hline $\begin{array}{l}\text { Instalar } \\
\text { Horário: }\end{array}$ & $\begin{array}{l}\text { Manta térmica ( ); massageador plantar ( ); massageador de MMII ( ) monitorização ( ) } \\
\text { nebulização ( ) }\end{array}$ & \\
\hline $\begin{array}{l}\text { Manter } \\
\text { Horário: }\end{array}$ & Meia elástica ( ); membros elevados ( ); decúbito ___ ( ); & \\
\hline $\begin{array}{l}\text { Aplicar } \\
\text { Horário: }\end{array}$ & $\begin{array}{l}\text { Compressa de gelo ou aparelho crio cuff em região } \\
\text { Compressas úmidas }(\mathrm{)} \text { ou geladas }(\mathrm{)} \text { em região ocular }(\mathrm{)}\end{array}$ & \\
\hline $\begin{array}{l}\text { Iniciar } \\
\text { Horário: }\end{array}$ & Soro de prescrição médica ( ); controle de irrigação contínua ( ) & \\
\hline $\begin{array}{l}\text { Controlar } \\
\text { Horário: }\end{array}$ & Débito de dreno, observando aspecto e volume ( ) sinais vitais a cada ___ minutos ( ) & \\
\hline Checar & Pulseira de identificação () & \\
\hline \multicolumn{2}{|c|}{ Enfermeira/carimbo } & \\
\hline
\end{tabular}

Condições da alta da RA para: UI ( ) SEMI ( ) UCO ( ) UTI ( )

\begin{tabular}{|c|c|}
\hline Estado de vigília & acordado ( ) dormindo( ) outros: \\
\hline Infusão & $\begin{array}{lc}\text { periférico ( ) central ( ) solução: } & \text { gotejamento: } \\
\text { bomba de infusão ( ) solução: } & \text { gotejamento: }\end{array}$ \\
\hline Analgesia & $\begin{array}{l}\text { dose única ( ) intermitente ( ) bomba de PCA: peridural ( ) plexo ( ) intra-articular ( ) venosa ( ) solução: } \\
\text { orientado quanto ao uso do PCA } \operatorname{sim}(\text { ) não ( ) }\end{array}$ \\
\hline Curativo & Limpo e seco ( ) com sujidade ( ) OBS: \\
\hline Dreno & tipo: \\
\hline Diurese & espontânea ( ) SVA ( ) SVD ( ) não apresentou na RA ( ) irrigação contínua ( ) outros: \\
\hline Perfusão periférica & 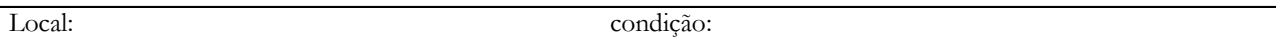 \\
\hline Massageador & MMII ( ) plantar ( ). Outro: \\
\hline Pertences & $\begin{array}{l}\text { pulseira de identificação ( ) tipóia ( ) material de síntese ( ) fita de vídeo ( ) chupeta ( ) cálculo: biliar ( ) renal ( } \\
\text { ) amuleto ( ) tipo: } \\
\text { exóteses ( ) } \\
\text { exames: } \operatorname{sim}(\text { ) vide check list não ( ) outros: }\end{array}$ \\
\hline Plantão & $\begin{array}{l}\text { enf. ( ) horário } \longrightarrow \text { h } \\
\quad \operatorname{enf}() \operatorname{tec}() \operatorname{aux}()\end{array}$ \\
\hline
\end{tabular}

Observações: 